\title{
Congenital heart surgeon's technical proficiency affects neonatal hospital survival
}

\author{
Jeffrey Shuhaiber, MD, ${ }^{a}$ Kimberlee Gauvreau, ScD, ${ }^{\mathrm{b}}$ Ravi Thiagarjan, MD, ${ }^{\mathrm{b}}$ Emile Bacha, MD, ${ }^{\mathrm{a}}$
} John Mayer, MD, ${ }^{a}$ Pedro del Nido, MD, ${ }^{a}$ and Frank Pigula, MD $^{\mathrm{a}}$

Objective: Risk factors for mortality after neonatal cardiac surgery have been seldom studied. We sought to identify contemporary risk factors for mortality and the impact of surgical technical performance on surgical outcomes after neonatal cardiac surgery.

Methods: We conducted a matched case-control study comparing 56 neonates who died after cardiac surgery (2002-2008) with 56 survivors matched by surgical procedure and year of surgery. Surgical efficacy for repair or palliation was graded using a reliable simple surgical technical score. Patient and surgical characteristics were compared for the survivors and nonsurvivors using paired analyses.

Results: There was no significant difference between patients who died and their matched controls in terms of age, Aristotle score, Risk Adjustment in Congenital Heart Surgery-1 category, and single versus biventricular repair. When compared with survivors, patients who died were more likely to be premature $(41 \% \mathrm{vs} 5 \%$, $P<.001)$, to weigh less than $2.5 \mathrm{~kg}(25 \%$ vs $9 \%, P=.05)$, and to have inadequate surgical repair or palliation $(55 \%$ vs $9 \%, P<.001)$. Cardiopulmonary bypass time was longer for the patients who died (median, 159 vs 133 minutes, $P=.002$ ). Highest postoperative lactate (median, 9.0 vs $6.0, P<.001$ ), use of extracorporeal membrane oxygenation ( $71 \%$ vs $13 \%, P<.001)$, and reoperation during the same admission $(75 \%$ vs $2 \%, P<.001)$ were also associated with death. In multivariable analysis, inadequate surgical repair or palliation (odds ratio, 11, $P=.02$ ) and need for postoperative extracorporeal membrane oxygenation (odds ratio, 5.1, $P=.009$ ) were the only risk factors associated with hospital death.

Conclusions: Our study highlights the need for optimal technical performance to minimize neonatal deaths. This has important implications when sustaining or developing a pediatric cardiac program. (J Thorac Cardiovasc Surg 2012;144:1119-24)

Earn CME credits at

http://cme.ctsnetjournals.org

Survival after neonatal cardiac surgery has been improving since the concept of early complete repair or palliation was introduced 20 years ago. ${ }^{1-3}$ Previous clinical research has established the qualitative and quantitative causes of death for all patients undergoing congenital heart surgery. Implementation of early repair in the newborn, when possible, is associated with the known benefits of attaining effective physiologic or anatomic circulation. However, both corrective and palliative neonatal cardiac surgery

\footnotetext{
From the Departments of Cardiovascular Surgery ${ }^{\mathrm{a}}$ and Cardiology, ${ }^{\mathrm{b}}$ Children's Hospital Boston, Boston, Mass

Disclosures: Authors have nothing to disclose with regard to commercial support.

Received for publication Dec 14, 2010; revisions received Jan 23, 2012; accepted for publication Feb 3, 2012; available ahead of print March 15, 2012.

Address for reprints: Jeffrey Shuhaiber, MD, University of Cincinnati, Department of

Surgery, 3333 Burnet Ave, Cincinnati, OH 45229 (E-mail: jeffrey.shuhaiber@ gmail.com).

$0022-5223 / \$ 36.00$

Copyright (C) 2012 by The American Association for Thoracic Surgery

doi:10.1016/j.jtcvs.2012.02.007
}

remain high-risk undertakings despite advances in neonatal medicine, neonatal monitoring, and surgical management.

The exact mechanisms leading to death after neonatal cardiac surgery are complex. However, the newborns undergoing cardiac surgery have limited physiologic reserves to compensate for perioperative adverse events. In addition to the newborn-related challenges of low birth weight, anatomic diversity, cardiopulmonary bypass, and other organizational and process factors can directly or indirectly influence hospital outcome.

This study sought to identify specific variables, including patient physiologic variables and technical outcomes of the surgery that might be associated with death after neonatal cardiac surgery. To accomplish this, we performed a matched case-control study of survivors and nonsurvivors undergoing neonatal cardiac surgery from Children's Hospital Boston.

\section{MATERIALS AND METHODS Patients}

The study was approved by the hospital institutional review board, and informed consent was waived. Patients were identified using the computerized database of the Departments of Cardiology and Cardiac Surgery at Children's Hospital Boston. Neonatal cardiac surgery was defined as any primary surgical procedure performed on newborns aged 30 days or less. 


\section{Abbreviation and Acronym \\ $\mathrm{ECMO}=$ extracorporeal membrane oxygenation}

We excluded patients who underwent heart transplantation, ligation of the patent ductus only, or resection of cardiac tumor as their primary procedure.

All these index neonatal cardiac surgeries were primary operations and did not include reoperations or primary catheter-based interventions. Neonates who survived congenital heart surgery (controls) and those who did not survive (cases) were included in the study.

From January 2002 to December 2008, a total of 65 patient deaths after neonatal cardiac surgery were identified. It is our programmatic policy to aggressively pursue the diagnosis of residual or unexpected cardiac lesions in postoperative patients unresponsive to medical therapy. As a result, early invasive and noninvasive imaging and intervention are performed urgently after neonatal cardiac surgery.

\section{Technical Performance Score}

A technical performance score previously developed by our division was adopted to determine the extent of successful completion of various mandatory surgical tasks associated with each specific surgical repair or palliation. ${ }^{4,5}$ For each subprocedure, score categories were defined as optimal, adequate, and inadequate. The parameters for score assessment were based on clinical, echocardiographic, and cardiac catheterization data and defined by consensus of physicians and surgeons at Children's Hospital Boston. Published technical assessment tools were available for single ventricle palliation and 2 ventricle repair (eg, tetralogy of Fallot, ventricular septal defect, transposition of great vessels). ${ }^{4,5}$ An overall score also was defined, wherein the operation was graded as optimal if all subprocedures were optimal; adequate if procedures were optimal or adequate, but none inadequate; and inadequate if 1 or more subprocedures was inadequate. For example, in case of tetralogy of Fallot repair, this was subdivided into individual entities according to the specific anatomic regions noted for repair: atrial and ventricular level, right ventricular outflow tract, and pulmonary artery work. In the case of ventricular septal defect entity, a small residual shunt $3 \mathrm{~mm}$ or less was considered adequate but inadequate if greater than $3 \mathrm{~mm}$ or it required a reintervention. In certain conditions (eg, unbalanced canal or hypoplastic left heart syndrome), technical score calculation was achieved by adopting subprocedures used previously in biventricular or single ventricle palliation. For example, for the entity-distal arch reconstruction, an adequate score was given if peak velocity was $3 \mathrm{~m} / \mathrm{s}$ or less by echocardiography, mild gradient was $20 \mathrm{~mm} \mathrm{Hg}$ or less, or there was successful intraoperative revision. An inadequate distal arch reconstruction was defined as peak velocity greater than $3 \mathrm{~m} / \mathrm{s}$ by echocardiography, more than $20 \mathrm{~mm} \mathrm{Hg}$, need for reintervention during initial hospital stay, and clinical evidence of coarctation.

Finding residual defects and calculating a score were based on various imaging modalities available in most patients; however, some patients could not be technically graded because of the severity of illness or lack of information, and therefore were excluded.

\section{Data Collection}

Clinical data (echocardiograms, clinical evaluation, and catheterization) were collected for assessment. Other variables included preoperative patient characteristics (age and weight at operation, prematurity, noncardiac anomalies, anatomic subtype, and presence of restrictive atrial septum), procedural characteristics (cardiopulmonary bypass times, circulatory arrest and regional cerebral perfusion times, aortic crossclamp times), postoperative characteristics (reinterventions, highest postoperative lactate), and use of extracorporeal membrane oxygenation (ECMO). Further, we assigned the surgeon's experience based on time as an attending surgeon $(<5$ or $\geq 5$ years).

\section{Study Design}

This was a retrospective, single-center study that used a matched casecontrol design. For each nonsurvivor, we screened our database for patient(s) with a similar surgical procedure during the same year of surgery who did not die. After generating a list of potential matches for each case, we randomly selected 1 matched survivor for each nonsurvivor to minimize selection bias.

\section{Statistical Analysis}

Patient and procedural characteristics were compared for the matched survivors and nonsurvivors using the Wilcoxon signed-rank test for continuous variables and McNemar's test for dichotomous variables. Conditional logistic regression was used for multivariable analysis. Variables with a $P$ value less than .1 in the bivariate analysis were considered for inclusion in the model, and a $P$ value less than .05 was set for retention in the final model.

\section{RESULTS}

\section{Study Population}

Between January 2002 and December 2008, a total of 65 patient deaths after neonatal cardiac surgery meeting eligibility criteria were identified. We excluded 9 nonsurvivors because of lack of an appropriate control match ( $n=4$; ventricular tumor resection, repair of total anomalous veins and hypoplastic left heart syndrome, repair of severe truncal insufficiency and interrupted arch) or data were incomplete to assess technical efficacy $(n=5)$. The remaining 56 patients who died in the hospital after neonatal cardiac surgery were matched with 56 patients who survived neonatal cardiac surgery. All patients had complete echocardiograms.

The cohort of cardiac diagnoses encompassed a full spectrum of common and uncommon congenital heart defects. Table 1 summarizes the distribution of cardiac diagnoses and extracardiac diagnoses among survivors and nonsurvivors after neonatal heart surgery included in the study. During the same time period, our program performed 817 neonatal cardiac surgical repairs or palliations with an overall mortality of $7.7 \%$ excluding transplantation.

\section{Comparison of Survivors Versus Nonsurvivors}

When survivors were compared with nonsurvivors with respect to patient and surgical characteristics, there were no statistically significant differences in terms of age, Aristotle scores, Risk Adjustment in Congenital Heart Surgery-1 risk category, surgeon's experience, timing of surgery (weekend vs weekday), or single versus biventricular repair (Table 2). When compared with survivors, patients who died were more likely to be premature $(<37$ weeks gestational age) $(41 \%$ vs $5 \%, P<.001)$ and to weigh less than $2.5 \mathrm{~kg}$ $(25 \%$ vs $9 \%, P=.05)$. Inadequate surgical repair or palliation $(55 \%$ vs $9 \%, P<.001)$ was also associated with death.

Intraoperatively, there were no statistical differences in aortic crossclamp time or circulatory arrest time between 
TABLE 1. Distribution of cardiac diagnoses and extracardiac diagnoses among survivors and nonsurvivors after congenital heart surgery

\begin{tabular}{|c|c|c|}
\hline & $\begin{array}{l}\text { No. of nonsurvivors } \\
(n=56)\end{array}$ & $\begin{array}{l}\text { No. of survivors } \\
\quad(\mathbf{n}=\mathbf{5 6})\end{array}$ \\
\hline \multicolumn{3}{|l|}{ HLHS } \\
\hline MA/AA & 12 & 11 \\
\hline MS/AA & 7 & 9 \\
\hline DORV & 1 & 0 \\
\hline MS/AS & 1 & 1 \\
\hline D-TGA/VSD & 3 & 3 \\
\hline ASD/MR/PDA & 1 & 1 \\
\hline DORV (subpulmonic VSD) & 1 & 1 \\
\hline DORV (subaortic VSD) & 1 & 1 \\
\hline Conoventricular VSD & 2 & 2 \\
\hline VSD/coarctation & 3 & 3 \\
\hline IAA/VSD & 2 & 2 \\
\hline TA type II & 4 & 4 \\
\hline TOF/PS & 4 & 5 \\
\hline TOF/PA & 2 & 3 \\
\hline TOF/coarctation & 1 & 0 \\
\hline TOF/aortic stenosis & 1 & 0 \\
\hline AVSD unbalanced & 3 & 3 \\
\hline DILV & 1 & 0 \\
\hline TA (type IIIB) & 3 & 3 \\
\hline PA/IVS & 3 & 4 \\
\hline \multicolumn{3}{|l|}{ Chromosome anomaly } \\
\hline $\mathrm{T} 21$ & 1 & 1 \\
\hline Deletion $4 \mathrm{q} 32.3$ & 1 & 0 \\
\hline Heterotaxy & 1 & 0 \\
\hline PHACE syndrome & 1 & 0 \\
\hline Corneilia-DeLange & 1 & 0 \\
\hline Rubenstein-Taebi & 1 & 0 \\
\hline Skeletal myopathy & 1 & 0 \\
\hline
\end{tabular}

Patients can have more than 1 diagnosis. HLHS, Hypoplastic left heart syndrome; $M A / A A$, mitral atresia/aortic atresia; MS/AA, mitral stenosis/aortic aorta; DORV, double-outlet right ventricle; $M S / A S$, mitral stenosis/aortic stenosis; $D-T G A$, dextro-transposition of the great arteries; $V S D$, ventricular septal defect; $A S D$, atrial septal defect; $M R$, mitral regurgitation; $P D A$, patent ductus arteriosus; IAA, interrupted aortic arch; $T A$, truncus arteriosus; $T O F$, tetralogy of Fallot; $P S$, pulmonary stenosis; PA, pulmonary atresia; $A V S D$, atrioventricular septal defect; DILV, double-inlet left ventricle; IVS, interventricular septum; $T 21$, trisomy of chromosome 21; PHACE, Posterior fossa abnormalities and other structural brain abnormalities; Hemangioma(s) of the cervical facial region; Arterial cerebrovascular anomalies; Cardiac defects, aortic coarctation, and other aortic abnormalities; Eye anomalies.

survivors and nonsurvivors (Table 3). Cardiopulmonary bypass time was longer for the patients who died (median, 159 vs 133 minutes; $P=.002$ ). For neonates who did not die, those who had ECMO had longer crossclamp times (median, 175 vs $130 ; P=.007)$. For those who did die, there was no difference in crossclamp time for those who had ECMO versus those who did not (median, 158 with ECMO, 164 with no ECMO; $P=.80$ ). Highest postoperative lactate (median, 9.0 vs $6.0 ; P<.001)$, use of ECMO $(71 \%$ vs $13 \%$, $P<.001)$, and reoperation during the same admission (75\% vs $16 \%, P<.001$ ) were strongly associated with death (Table 4). The surgical indications for reoperations are shown
TABLE 2. Comparison of demographic and surgical characteristics for matched neonatal cohorts

\begin{tabular}{|c|c|c|c|}
\hline & $\begin{array}{c}\text { Nonsurvivor } \\
(\mathrm{n}=\mathbf{5 6})\end{array}$ & $\begin{array}{c}\text { Survivors } \\
(\mathrm{n}=\mathbf{5 6})\end{array}$ & $P$ value \\
\hline Weight $(\mathrm{kg}<2.5)$ & $14(25)$ & $5(9)$ & .05 \\
\hline Premature & $23(41)$ & $3(5)$ & $<.001$ \\
\hline Surgery on weekend & $1(2)$ & $1(2)$ & 1.0 \\
\hline Type of ventricle repair & & & .38 \\
\hline Single ventricle & $34(61)$ & $36(65)$ & \\
\hline Biventricular & $22(39)$ & $19(35)$ & \\
\hline RACHS- 1 risk category & & & 1.0 \\
\hline 1 & $1(2)$ & $2(4)$ & \\
\hline 2 & $6(11)$ & $11(20)$ & \\
\hline 3 & $15(27)$ & $4(7)$ & \\
\hline 4 & $7(13)$ & $10(18)$ & \\
\hline 6 & $27(48)$ & $29(52)$ & \\
\hline Surgeon experience & & & .61 \\
\hline$<5 \mathrm{y}$ & $16(29)$ & $13(23)$ & \\
\hline$\geq 5 \mathrm{y}$ & $40(71)$ & $43(77)$ & \\
\hline Aristotle basic score & $11.5(6.0-14.5)$ & $14.5(6.0-14.5)$ & .72 \\
\hline Aristotle complexity & & & .98 \\
\hline 2 & $14(25)$ & $14(25)$ & \\
\hline 3 & $7(13)$ & $6(11)$ & \\
\hline 4 & $35(62)$ & $36(64)$ & \\
\hline Surgical efficacy & & & $<.001$ \\
\hline Optimal & $17(30)$ & $47(84)$ & \\
\hline Adequate & $8(14)$ & $4(7)$ & \\
\hline Inadequate & $31(55)$ & $5(9)$ & \\
\hline
\end{tabular}

in Table 5. For those with adequate outcome, 6 of $12(50 \%)$ underwent reoperation. For those who sustained an inadequate outcome, $92 \%$ underwent reoperation $(P<.001)$.

On multivariable analysis of factors associated with neonatal cardiac surgical mortality, inadequate surgical repair or palliation (odds ratio, $11 ; P=.02$ ) and use of ECMO (odds ratio, $5.1 ; P=.009$ ) were the only 2 variables associated with hospital death after neonatal cardiac surgery.

\section{DISCUSSION}

Many advances during the past decade in neonatal cardiac surgery have resulted in a definite reduction in mortality and morbidity. ${ }^{6}$ For example, existing mortalities for hypoplastic left heart syndrome undergoing stage I have decreased to less than $20 \%$ in most centers. ${ }^{7,8}$ Nonetheless, neonatal cardiac surgery remains a high-risk undertaking demanding consistent optimal technical repair or palliation, as well as comprehensive intensive care support and surgical management. Definitive causes of death after cardiac surgery have been attributed to a host of pathophysiologic factors, conduct of surgery, adequacy of repair or palliation, and postoperative management including the use of ECMO. Until recently, the definition of optimal surgical performance in congenital heart surgery was measured by hospital mortality usually in the form of cumulative sum analysis. 
TABLE 3. Comparison of intraoperative characteristics for matched neonatal cohorts

\begin{tabular}{lccc}
\hline & $\begin{array}{c}\text { Nonsurvivor } \\
(\mathbf{n}=\mathbf{5 6})\end{array}$ & $\begin{array}{c}\text { Survivors } \\
(\mathbf{n}=\mathbf{5 6})\end{array}$ & $\begin{array}{c}\boldsymbol{P} \\
\text { value }\end{array}$ \\
\hline CXT $(\mathrm{n}=49,49)$ & $76(10-189)$ & $67(20-179)$ & .21 \\
CAT $(\mathrm{n}=16,16)$ & $43(4-189)$ & $34(0-60)$ & .61 \\
CPB $(\mathrm{n}=48,48)$ & $159(87-389)$ & $133(86-422)$ & .002 \\
\hline
\end{tabular}

$C X T$, Crossclamp time; $C A T$, circulatory arrest time; $C P B$, cardiopulmonary bypass time.

Both the Aristotle and Risk Adjustment in Congenital Heart Surgery-1 scoring systems were developed to allow for riskadjusted mortality outcomes in children with congenital heart disease undergoing surgical intervention. ${ }^{9,10}$ However, it did not address the efficacy of the repair or palliation in congenital heart surgery.

In the multivariable analysis, lower technical scores and use of ECMO were the 2 independent variables associated with death. We will discuss the role of these predictors in light of our research findings with the aim of improving outcome of neonatal cardiac surgery.

\section{Surgical Technical Performance}

Among the nonsurvivors, only $30 \%$ had optimal repair, $15 \%$ had adequate repair, and $55 \%$ had inadequate repair. Inadequate technical scores correlated statistically with death, and optimal scores correlated with survival-84\% (optimal), $7 \%$ (adequate), and $9 \%$ (inadequate) $(P<.001)$ - suggesting a strong survival impact of technical performance during neonatal cardiac surgery. By adopting this technical score, several important factors are revealed. Among the nonsurvivors after single ventricle palliation, systemic pulmonary shunt-related obstruction or increased pulmonary blood flow compared with systemic blood flow (of which only 1 was a right ventricular to pulmonary artery conduit) and aortic arch narrowing were the most frequent problems requiring a reintervention or reoperation, which did result in death. More specifically, in the Norwood cohort, shunt reinterventions and aortic arch re-reconstructions were the most frequent reoperations among nonsurvivors. However, re-repair of residual ventricular septal defects followed by re-repair of

TABLE 4. Comparison of postoperative characteristics for matched neonatal cohorts

\begin{tabular}{llll}
\hline & $\begin{array}{c}\text { Nonsurvivor } \\
(\mathbf{n}=\mathbf{5 6})\end{array}$ & $\begin{array}{c}\text { Survivors } \\
(\mathbf{n}=\mathbf{5 6})\end{array}$ & $\begin{array}{c}\boldsymbol{P} \\
\text { value }\end{array}$ \\
\hline Highest postoperative lactate & $9.0(2.6-23.5)$ & $6.0(1.5-27.1)$ & $<.001$ \\
ECMO & $40(71)$ & $7(13)$ & $<.001$ \\
ECMO to support CPR & $20(36)$ & $4(7)$ & $<.001$ \\
Reoperation (including for & $42(75)$ & $9(16)$ & $<.001$ \\
$\quad$ bleeding, missed diagnosis) & & & \\
\hline $\begin{array}{l}\text { ECMO, Extracorporeal membrane oxygenation; } C P R, \text { cardiopulmonary resuscita- } \\
\text { tion. }\end{array}$
\end{tabular}

TABLE 5. Reinterventions after primary operation

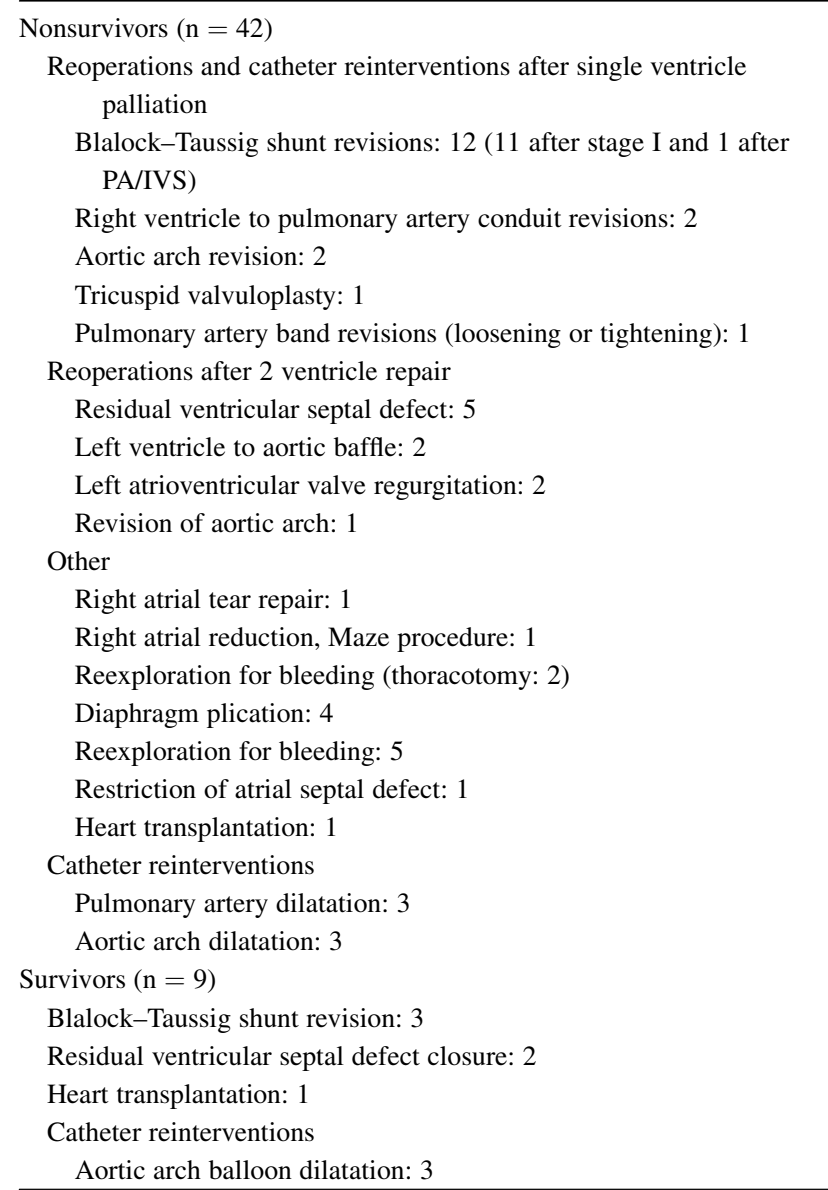

Patients may have more than 1 reintervention or no reintervention. PA, Pulmonary artery; IVS, interventricular septum.

atrioventricular valve regurgitation and aortic arch were more common reinterventions in the biventricular repair cohort.

In an autopsy study of death after the Norwood procedure from Children's Hospital Boston 15 years ago, Bartram and colleagues ${ }^{11}$ identified the causes of death after 122 Norwood procedures. They found the most common causes were impairment of coronary perfusion (33 patients, $27 \%$ ), excessive pulmonary blood flow (23 patients, $19 \%$ ), obstruction of pulmonary arterial blood flow (21 patients, $17 \%$ ), neoaortic obstruction (17 patients, $14 \%$ ), and right ventricular failure (16 patients, $13 \%)$. Among the nonsurvivors, coronary obstruction was a far less common problem in our matched population, yet aortic arch reconstruction and pulmonary blood flow regulation were frequently fatal problems identified by Bartram and colleagues. ${ }^{11}$ We observed 2 patients who did not survive the Norwood procedure and died after irreversible poor ventricular function. Catheterization angiography confirmed no coronary flow. The decision at that time was not to reoperate on these patients. 
Although the leading causes of death after the Norwood procedure identified by Bartram and colleagues ${ }^{11}$ are largely correctable, we have made some surgical progress over the last 3 decades since the original Norwood procedure. Technical modifications, such as division of the diminutive ascending aorta with side-to-side or end-to-end anastomosis to the pulmonary artery, with tubularization of the aortic arch, seems to be reproducible and to avoid coronary insufficiency after stage 1 operations. Other strategies to avoid arch obstruction have been used, with some encouraging results. For instance, recurrent arch obstruction has been countered by resection of the coarctation shelf, with reapproximation of the aorta directly or using the interdigitation technique, and the Sano modification of the right ventricle-pulmonary artery conduit seems to improve early survival in a randomized trial. ${ }^{12}$ However, the fixed size of the systemic or pulmonary shunt is limiting and could lead to over- or under-circulation despite selective use of 3-mm Blalock-Taussig shunt for infants weighing less than $3 \mathrm{~kg}$.

Clearly, there is always room to reduce time for surgery while aiming for optimal technical performance. We noted increased bypass times for the nonsurvivors, yet the crossclamp times were nearly identical. A possible reason for this may be the attempts at weaning from cardiopulmonary bypass given the cardiac function and contractility.

Although the purpose of this study is to confirm prior anecdotal evidence that surgical outcomes are heavily dependent on technical results, we did not focus on the causes of inadequate repair. The mechanism for technical errors is still one that eludes us from time to time. ${ }^{13}$ In broad categories, causes of inadequate surgical repair can be classified as follows: (1) the challenges related to the patient in general and the specific anatomic lesion, that is, preoperative planning; (2) surgical instrument failure, technical factors (eg, suture size and breakage), excessive muscular resection, and the interface among these factors; and (3) operator proficiency and ability to execute surgical repair or palliation with minimal errors or repetition of procedural components involved.

Categories 1 and 2 are difficult to predict because they are based on cognitive comprehension at the time of multidisciplinary discussions and imaging. Attempts at improving preoperative knowledge of the lesion using tangible 3-dimensional models may be helpful. ${ }^{14} \mathrm{~A}$ safe culture in the operating room by timely recognition and risk-averse behavior is essential to minimize any further implications or ramifications thereof. ${ }^{15,16}$ A supportive perioperative team throughout from admission to discharge is key to success in highly specialized environments. For category 3 , there is a learning curve to undergo, and this spans an undefined period of time along the career span of the surgeon. However, experienced surgeons have witnessed this in lesions such as the ventricular septal defect and arterial switch operation, and through the process of auditing and retraining, optimal surgical procedures were achieved and maintained long term. ${ }^{17,18}$

\section{Extracorporeal Membrane Oxygenation After Neonatal Cardiac Surgery}

ECMO has achieved $40 \%$ to $60 \%$ survival to discharge after congenital heart surgery when deployed in a timely manner. ${ }^{19}$ More specifically, ECMO after stage I reconstruction for hypoplastic left heart was lifesaving in approximately one third of infants who would otherwise have died. However, previous research has shown that re-repair for residual defects while on $\mathrm{ECMO}^{20}$ was associated with poor outcomes. In a study from the Toronto Hospital for Sick Children before 1994, 100\% who could not be weaned after cardiopulmonary bypass because of residual defects died while on ECMO. Among those who required postcardiotomy ECMO without residual defects, $33.3 \%$ died. The authors concluded that the presence of irreparable residual defects was a contraindication to ECMO. Although our study design was aimed at determining differences in predictor outcomes for matched survivors and nonsurvivors, ECMO was commonly associated with nonsurvivors who experienced suboptimal surgical repair or palliation.

The combination of low birth weight, prematurity, and congenital heart disease in the newborn is a challenge to the medical care team. Conservative surgical wisdom might suggest allowing these patients to grow by adding on weight, and reaching beyond the $2.5 \mathrm{-kg}$ threshold might reduce the risk of multiorgan failure after cardiopulmonary bypass. $^{21,22}$ However, an earlier series from our own experience $^{6}$ showed that delayed repair carried higher mortality and morbidity.

Our findings are consistent with a recent study by Lechner and colleagues, ${ }^{22}$ which was based on 46 neonates with low birth weight and showed that history of prematurity was not associated with a higher mortality; however, the number of patients was small.

We have maintained an aggressive approach to early surgical repair and early imaging (echocardiography, magnetic resonance imaging, and catheterization) for patients who demonstrate what we consider unsatisfactory clinical progress after neonatal cardiac surgery. We recently showed that intraoperative imaging can change surgical outcome intraoperatively in a series of complex congenital cardiac surgical cases. $^{23}$

\section{Limitations}

Study limitations are primarily related to the retrospective study design analyzing a prospectively maintained database. The current study did not assess other secondary factors, such as process of care, structure, and context of our institutional organization. 
Given the limited number of survivor patients who were available to match for each death, it was not feasible to match for surgeon experience or to more than 1 matching survivor. Among the nonsurvivors, 15 patients had optimal technical repair but died of poor ventricular function for unknown reasons, reemphasizing the importance of other aspects of cardiopulmonary bypass and myocardial protection management during neonatal surgery.

\section{CONCLUSIONS}

When compared with matched survivors, death after neonatal cardiac surgery is associated with inadequate surgical repair or palliation and use of ECMO. Further work is needed to find ways to attain and maintain optimal technical performance during all neonatal cardiac procedures.

\section{References}

1. Norwood WI, Pigott JD. Recent advances in cardiac surgery. Pediatr Clin North Am. 1985;32:1117-24.

2. Mee RB. Current status of cardiac surgery in childhood. Prog Pediatr Surg. 1991; 27:148-69.

3. Pawade A, Waterson K, Laussen P, Karl TR, Mee RB. Cardiopulmonary bypass in neonates weighing less than $2.5 \mathrm{~kg}$ : analysis of the risk factors for early and late mortality. J Card Surg. 1993;8:1-8.

4. Larrazabal LA, del Nido PJ, Jenkins KJ, Gauvreau K, Lacro R, Colan SD, et al. Measurement of technical performance in congenital heart surgery: a pilot study. Ann Thorac Surg. 2007;83:179-84.

5. Bacha EA, Larrazabal LA, Pigula FA, Gauvreau K, Jenkins KJ, Colan SD, et al. Measurement of technical performance in surgery for congenital heart disease: the stage I Norwood procedure. J Thorac Cardiovasc Surg. 2008;136:993-7, 997.e1-2.

6. Chang AC, Hanley FL, Lock JE, Castaneda AR, Wessel DL. Management and outcome of low birth weight neonates with congenital heart disease. J Pediatr. 1994;124:461-6.

7. Tabbutt S, Dominguez TE, Ravishankar C, Marino BS, Gruber PJ, Wernovsky G, et al. Outcomes after the stage I reconstruction comparing the right ventricular to pulmonary artery conduit with the modified Blalock Taussig shunt. Ann Thorac Surg. 2005;80:1582-91.
8. Rüffer A, Danch A, Gottschalk U, Mir T, Lacour-Gayet F, Haun C, et al. The Norwood procedure-does the type of shunt determine outcome? Thorac Cardiovasc Surg. 2009;57:270-5.

9. Jenkins KJ, Gauvreau K. Center-specific differences in mortality: preliminary analyses using the Risk Adjustment in Congenital Heart Surgery (RACHS-1) method. J Thorac Cardiovasc Surg. 2002;124:97-104.

10. Lacour-Gayet F, Clarke DR, Aristotle Committee. The Aristotle method: a new concept to evaluate quality of care based on complexity. Curr Opin Pediatr. 2005; $17: 412-7$

11. Bartram U, Grünenfelder J, Van Praagh R. Causes of death after the modified Norwood procedure: a study of 122 postmortem cases. Ann Thorac Surg. 1997;64:1795-802.

12. Ohye RG, Sleeper LA, Mahony L, Newburger JW, Pearson GD, Lu M, et al. Pediatric Heart Network Investigators. Comparison of shunt types in the Norwood procedure for single-ventricle lesions. N Engl J Med. 2010;362:1980-92.

13. Bognár A, Barach P, Johnson JK, Duncan RC, Birnbach D, Woods D, et al. Errors and the burden of errors: attitudes, perceptions, and the culture of safety in pediatric cardiac surgical teams. Ann Thorac Surg. 2008;85:1374-81.

14. Mottl-Link S, Hübler M, Kühne T, Rietdorf U, Krueger JJ, Schnackenburg B, et al. Physical models aiding in complex congenital heart surgery. Ann Thorac Surg. 2008;86:273-7.

15. Nagpal K, Vats A, Lamb B, Ashrafian H, Sevdalis N, Vincent C, Moorthy K. Information transfer and communication in surgery: a systematic review. Ann Surg. 2010;252:225-39.

16. Vincent C, Batalden P, Davidoff F. Multidisciplinary centres for safety and quality improvement: learning from climate change science. BMJ Qual Saf. 2011; 20(Suppl 1):i73-8.

17. de Leval MR. Lessons from the arterial-switch operation. Lancet. 2001;357:1814.

18. de Leval MR. Human factors and surgical outcomes: a Cartesian dream. Lancet. 1997;349:723-5.

19. Thiagarajan RR, Laussen PC, Rycus PT, Bartlett RH, Bratton SL. Extracorporeal membrane oxygenation to aid cardiopulmonary resuscitation in infants and children. Circulation. 2007;9(116):1693-700.

20. Black MD, Coles JG, Williams WG, Rebeyka IM, Trusler GA, Bohn D, et al. Determinants of success in pediatric cardiac patients undergoing extracorporeal membrane oxygenation. Ann Thorac Surg. 1995;60:133-8.

21. Oppido G, Napoleone CP, Formigari R, Gabbieri D, Pacini D, Frascaroli G, et al. Outcome of cardiac surgery in low birth weight and premature infants. Eur J Cardiothorac Surg. 2004;26:44-53.

22. Lechner E, Wiesinger-Eidenberger G, Weissensteiner M, Hofer A, Tulzer G, Sames-Dolzer E, et al. Open-heart surgery in premature and low-birth-weight infants-a single-centre experience. Eur J Cardiothorac Surg. 2009;36:986-91.

23. Shuhaiber JH, Bergersen L, Pigula F, Emani S, McElhinney D, Marshall A, et al. Intraoperative assessment after pediatric cardiac surgical repair: initial experience with C-arm angiography. J Thorac Cardiovasc Surg. 2010;140:e1-3. 